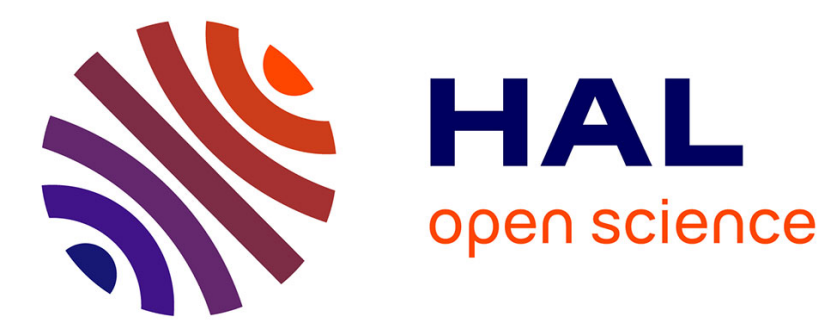

\title{
Bearing capacity of strip footings with horizontal confinement
}

Jean Salençon

\section{To cite this version:}

Jean Salençon. Bearing capacity of strip footings with horizontal confinement. Comptes rendus de l'Académie des sciences. Série IIb, Mécanique, 2003, 331, pp.319-324. 10.1016/S1631-0721(03)000718. hal-00111382

\section{HAL Id: hal-00111382 \\ https://hal.science/hal-00111382}

Submitted on 22 Jul 2019

HAL is a multi-disciplinary open access archive for the deposit and dissemination of scientific research documents, whether they are published or not. The documents may come from teaching and research institutions in France or abroad, or from public or private research centers.
L'archive ouverte pluridisciplinaire HAL, est destinée au dépôt et à la diffusion de documents scientifiques de niveau recherche, publiés ou non, émanant des établissements d'enseignement et de recherche français ou étrangers, des laboratoires publics ou privés. 


\title{
Bearing capacity of strip footings with horizontal confinement
}

\author{
Jean Salençon \\ École polytechnique, laboratoire de mécanique des solides, 91128 Palaiseau cedex, France
}

\begin{abstract}
For a strip footing under axial loading, the bearing capacity is influenced by the presence of rigid walls confining the foundation soil. This problem is investigated within the framework of the theory of yield design, considering both a perfectly rough and a frictionless contact condition at the interfaces with the walls in the case of a purely cohesive soil. Upper bounds for the correction factor to be applied to the classical value of the bearing capacity are determined, as functions of the nondimensional geometric parameter of the problem, through the kinematic approach, implementing virtual velocity fields inspired from the solution to the problem of inverted extrusion. In the perfectly rough case, it appears that the new upper bound is a significant improvement of those already available. A very simple relationship is established, which derives the upper bound for the frictionless walls from the upper bound for the rough walls. A general conclusion of the analysis is that, for the values of the geometric parameter that are likely to be encountered in practice, the increase in the bearing capacity due to the presence of the rigid walls remains very small.
\end{abstract}

\section{Résumé}

La capacité portante des fondations superficielles en présence de parois rigides. La présence de parois rigides au voisinage d'une fondation superficielle influe sur la capacité portante de cette fondation. On étudie ce problème dans le cas d'un sol cohérent sans frottement interne en supposant que le contact avec les parois est soit parfaitement rugueux soit sans frottement. En mettant en œuvre l'approche cinématique du calcul à la rupture avec des champs de vitesse virtuels inspirés de l'étude de l'extrusion inverse, on détermine des bornes supérieures pour le facteur de correction à appliquer au coefficient classique de capacité portante, en fonction du paramètre géométrique adimensionnel du problème. Dans le cas des parois rugueuses, la nouvelle borne supérieure se révèle significativement meilleure que celles disponibles jusqu'alors. Une relation simple est établie qui permet d'obtenir la borne supérieure pour les parois lisses à partir de celle valable pour les parois rugueuses. En conclusion de l'analyse, il apparaît que, pour les valeurs du paramètre géométrique réalistes du point de vue de la pratique, l'accroissement de capacité portante dû à la présence des parois rigides demeure faible.

Keywords: Soils; Bearing capacity; Confinement; Extrusion; Foundation; Yield design

Mots-clés : Sols ; Calcul à la rupture ; Extrusion ; Fondation ; Force portante

E-mail address: salencon@1ms.polytechnique.fr (J. Salençon). 


\section{The problem under investigation}

In [1] we presented the results of a theoretical determination of the bearing capacity of strip footings submitted to axial loading, when the soil foundation, with infinite thickness, is limited in the horizontal directions by rigid vertical walls. The soil foundation was either purely cohesive or frictional assuming a perfectly rough contact condition at the interfaces with the footing and with the rigid walls. The major part of the analysis was devoted to obtaining upper bound estimates within the framework of the yield design theory [2] by revisiting the solution to the problem of the bearing capacity of a surface footing on a soil layer with limited thickness. The virtual velocity fields, which were implemented in the upper bound approach, took place in a soil layer whose thickness was strictly proportional to the gap between the edge of the foundation and the adjacent wall. The same problem will be investigated again, in the case of a purely cohesive soil, in both cases of a perfectly rough or a frictionless (smooth) contact condition (with no tensile strength) at the rigid walls, through a kinematic approach using virtual velocity fields inspired from the analysis of inverted extrusion [3]. The notations are kept as in [1]. The width of the footing is denoted $B=2 b$. The distance between the edge of the footing and the corresponding rigid containing wall is denoted $L$. The cohesion of the foundation soil is $c_{\mathrm{u}}$ with the Tresca strength criterion.

The axial force acting on the footing is denoted $F$ (more precisely, $F$ is the axial force per unit transversal length acting on the footing). The problem is treated as a 2-dimensional one. The theoretical bearing capacity is defined as $p_{\text {ult }}=F / B$ when $F$ reaches its maximum value from the yield design point of view.

In consideration of the parameters of the problem, the non-dimensional expression of $p_{\text {ult }}$ can be written as:

$$
p_{\text {ult }}=c_{\mathrm{u}} K_{\mathrm{c}}\left(\frac{L}{b}\right) N_{\mathrm{c}} \quad \text { with } N_{\mathrm{c}}=\pi+2 \text { and } K_{\mathrm{c}}(\infty)=1
$$

where $K_{\mathrm{c}}(L / b)$ is the correction factor which takes the confining effect into account. In order to distinguish the "rough" and the "smooth" case a superscript "r" or "s" will be introduced in Eq. (1), namely: $K_{\mathrm{c}}^{\mathrm{r}}(L / b)$ and $K_{\mathrm{c}}^{\mathrm{s}}(L / b)$.

\section{Perfectly rough contact condition with the rigid walls}

\section{1. $L / b \geqslant 2$}

Referring to Prandtl solution and to the extension of its stress-field by Shield as in [1], it comes out that:

$$
\forall \frac{L}{b} \geqslant 2, \quad K_{\mathrm{c}}^{\mathrm{r}}\left(\frac{L}{b}\right)=1
$$

\section{2. $0<L / b<2$}

Investigating the range $0<L / b<2$, we now consider the virtual velocity field constructed, through the use of Geiringer's equations [4] on the symmetrical slip-line field presented in Fig. 1, which is inspired from [3]. Fig. 1 also shows the corresponding hodograph [5] when the footing is given a vertical virtual translation motion with velocity $\widehat{U}$ : zone $A^{\prime} M^{\prime} S M A$ moves vertically as a rigid block with velocity $\widehat{U}$; across $A^{\prime} M^{\prime} S G$ and $G^{\prime} R^{\prime} Q^{\prime} S M A$ the velocity field is discontinuous, with a tangential jump equal to $\widehat{U} \sqrt{2} / 2$; beneath $G^{\prime} R^{\prime} Q^{\prime} S G$ the soil is motionless; $G^{\prime} A^{\prime} C^{\prime}$ has a translation rigid body motion; since the hodograph and the slip-line field happen to be geometrically similar and orthogonal to each other, the velocity $O a^{\prime}$ of $G^{\prime} A^{\prime} C^{\prime}$ is normal to the straight line $A S$ with $\widehat{U} L / b$ as vertical component (symmetrically for $G A C$ ); the velocity field in the rest of the soil layer is described in the hodograph.

Applying the upper bound approach of the theory of Yield design would require the explicit computation of the maximum resisting rate of work in that virtual velocity field, which should then be compared with the work of the 


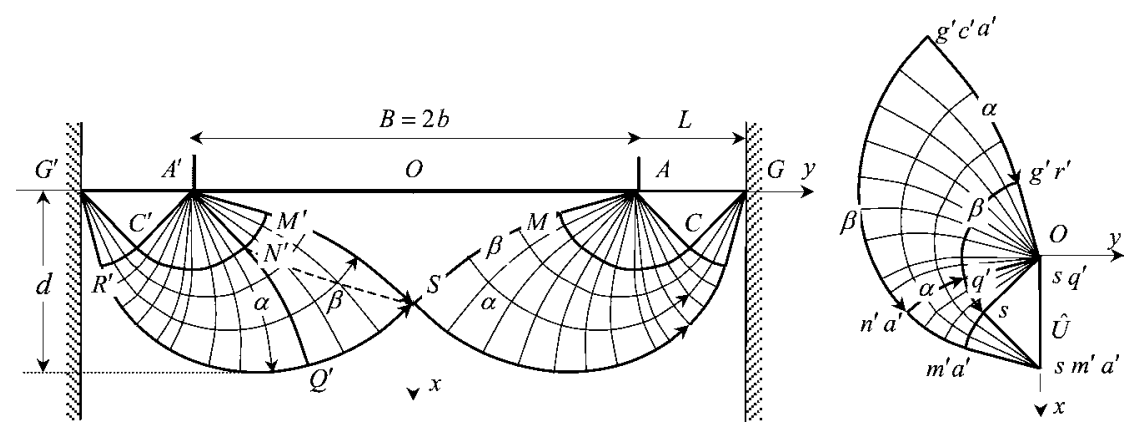

Fig. 1. Slip-line field and hodograph for perfectly rough walls when $L / b \geqslant 0.29$.

external forces. As a matter of fact a short cut can be taken since Fig. 1 makes it possible to exhibit a so-called "incomplete solution" as introduced by Bishop [6]. Starting from the stress-free surface boundary condition along $A^{\prime} G^{\prime}$ and $A G$ and assuming the vertical direction to be the direction of maximum pressure there, a stress-field is constructed, which is in equilibrium with zero body forces and which saturates the Tresca strength criterion. The network of $\alpha$ and $\beta$ lines in Fig. 1 is the network of characteristics of this stress-field and the Hencky equations [3], which are satisfied along these lines, determine the stress-field in the region under concern. Point $S$, where the two symmetric parts of the network meet each other, is situated on the symmetry axis of the footing and is determined from the condition that the vertical and horizontal directions be the principal axes for the stress-field: hence arcs $C^{\prime} R^{\prime}$ and $M^{\prime} N^{\prime}$ are equal to each other. Only a partial stress-field being constructed does not make it possible to refer to the static approach of the theory of yield design. But, in consideration of Ewing and Hill's theorem [7], since the orientations of the $\alpha, \beta$ network and of its image in the hodograph are interchanged, the corresponding stressand velocity fields can be combined to produce an incomplete solution [6] with the benefit that the bearing capacity computed by means of the partial stress-field is just the upper bound estimate given by the virtual velocity field.

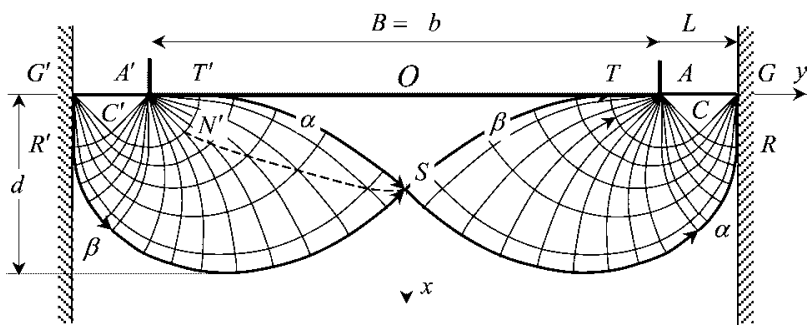

Fig. 2. Slip-line field for perfectly rough walls when $0<L / b<0.29$.

The network in Fig. 1 remains valid until $R^{\prime}$ meets the rigid wall, which corresponds to $M^{\prime}$ meeting the footing. With reference to the geometric parameters of the problem this amounts to: $L / b \geqslant 0.29$. For lower values of $L / b$ the network is extended, as shown in Fig. 2, with $\beta$ lines tangent to the wall and $\alpha$ lines tangent to the footing on the left-hand side and symmetrically on the right-hand side. The entire reasoning remains valid.

After constructing the network numerically through classical procedures, the stress-field is determined explicitly at each node of the mesh and integration along $A^{\prime} M^{\prime} S$ (or, more conveniently, along $A^{\prime} N^{\prime} S$ ), in order to obtain the corresponding upper bound for the bearing capacity, is straightforward. Referring to Eq. (1), we write:

$$
p_{\mathrm{ult}}=c_{\mathrm{u}} K_{\mathrm{c}}^{\mathrm{r}}\left(\frac{L}{b}\right) N_{\mathrm{c}} \leqslant c_{\mathrm{u}}\left[K_{\mathrm{c}}^{\mathrm{r}}\left(\frac{L}{b}\right)\right]^{\prime} N_{\mathrm{c}}
$$

where $\left[K_{\mathrm{c}}^{\mathrm{r}}(L / b)\right]^{\prime}$ is the upper bound for the correction factor $K_{\mathrm{c}}^{\mathrm{r}}(L / b)$. 
The results are presented in Fig. 3 together with the upper bound proposed previously [1] and with the closedform upper bound recently obtained by Puzrin and Randolph [8] through an innovative method. This one becomes rapidly greater than the others when $L / b$ decreases and, in a comparison with [1], we observe that a significant reduction of the upper bound for the correction factor has been gained from the approach presented here: for the same value of $L / b$, the increase in the bearing capacity due to horizontal confinement is now reduced by some $50 \%$. This strengthens the conclusion that, for practically relevant values of $L / b$, the increase in the bearing capacity due to confinement remains very small: smaller than $10 \%$ for $L / b>0.72$ and smaller than $20 \%$ for $L / b>0.45$.

It may also be recalled that in the solution proposed in [1], the thickness of the layer where the virtual velocity field took place was kept equal to $d=L \sqrt{2} / 2$ for any value of $L / b \leqslant 2$, so that $d / b$ decreased to 0 in proportion with $L / b$. In the present case it is observed in Fig. 3 that the decrement of $d / b$ with $L / b$ due to the presence of the rigid walls is limited.
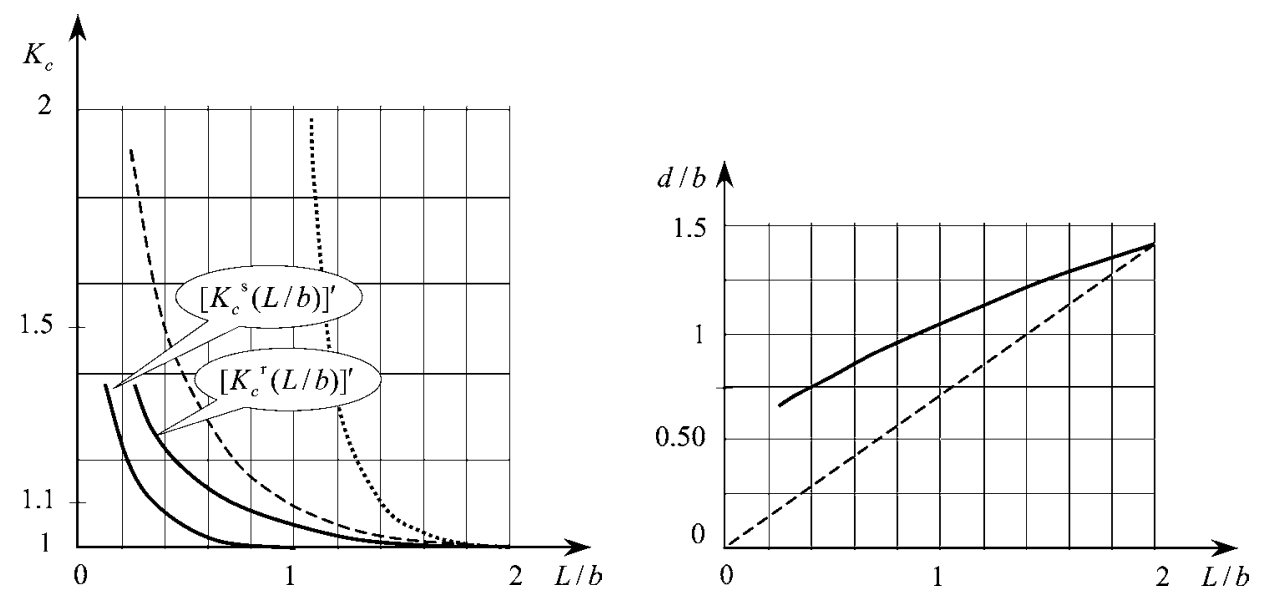

Fig. 3. Influence of confinement on the bearing capacity: perfectly rough walls $\left[K_{\mathrm{c}}^{\mathrm{r}}(L / b)\right]^{\prime}$, frictionless walls $\left[K_{\mathrm{c}}^{\mathrm{s}}(L / b)\right]^{\prime}$, previous upper bound (dashed line), Puzrin and Randolph [8] upper bound (dotted line).

\section{Frictionless contact condition with the rigid walls}

Since introducing a frictionless contact condition instead of the perfectly rough one results in reducing the resistance of the corresponding interfaces, it is clear from the definition of the bearing capacity that:

$$
\forall \frac{L}{b}>0, \quad K_{\mathrm{c}}^{\mathrm{s}}\left(\frac{L}{b}\right) \leqslant K_{\mathrm{c}}^{\mathrm{r}}\left(\frac{L}{b}\right)
$$

Therefore $\left[K_{\mathrm{c}}^{\mathrm{r}}(L / b)\right]^{\prime}$ remains an upper bound for the correction factor in the case of the frictionless contact condition. But we can also anticipate that new virtual velocity fields involving slipping of the soil along the walls may now be considered, which would lead to better upper bound estimates for $K_{\mathrm{c}}^{\mathrm{s}}(L / b)$.

\section{1. $L / b \geqslant 1$}

Such a virtual velocity field can be produced from Prandtl classical solution, as shown in Fig. 4, for values of $L / b$ within the range $1 \leqslant L / b \leqslant 2$. The footing being given a rigid body vertical translation motion with the velocity $\widehat{U}$, the classical virtual velocity field is maintained in $A^{\prime} B A$, in $A^{\prime} B C^{\prime}$ and in $A B C$; in $A^{\prime} C^{\prime} E^{\prime} F^{\prime}$ (resp. $A C E F$ ) we still encounter a virtual rigid body translation motion parallel to $C^{\prime} E^{\prime}$ (resp. $C E$ ) with velocity $\widehat{U} \sqrt{2} / 2 ; E^{\prime} F^{\prime}$ (resp. $E F)$ is a velocity discontinuity line such that $E^{\prime} F^{\prime} G^{\prime}($ resp. $E F G)$ receive the vertical velocity $\widehat{U}$. 


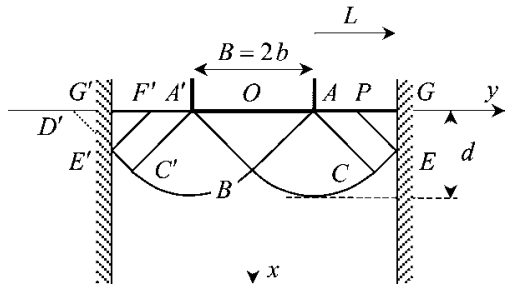

Fig. 4. Slip-line field for frictionless walls when $1 \leqslant L / b \leqslant 2$.

This virtual velocity field can still be combined with the stress-field of Prandtl solution restricted to $G^{\prime} A^{\prime} A G E B E^{\prime}$ in order to produce an incomplete solution. It follows that the corresponding upper bound for the correction factor is just:

$$
1 \leqslant \frac{L}{b} \leqslant 2, \quad K_{\mathrm{c}}^{\mathrm{s}}\left(\frac{L}{b}\right)=1
$$

\section{2. $0<L / b \leqslant 1$}

For $0<L / b \leqslant 1$, Fig. 5 presents the virtual velocity field derived from Fig. 1 by truncating the slip-line field with the frictionless rigid walls passing through points $C$ and $C^{\prime}$. The hodograph gives the complete description of the virtual mechanism: in $A^{\prime} P^{\prime} R^{\prime} S R C A A^{\prime}$ the velocity field is the same as in Fig. 1; it is discontinuous across $R^{\prime} P^{\prime} A^{\prime}$ (and symmetric) with a jump equal to $\widehat{U} \sqrt{2} / 2$; finally $A^{\prime} C^{\prime} G^{\prime}$ and $A C G$ move vertically with velocity $\widehat{U} b / L$. Looking for an incomplete solution with this virtual velocity field, it is clear that restricting the stress field constructed in the "rough" case to the zone limited by the rigid walls in the "smooth" case complies with the frictionless contact condition. Comparison of the orientations of the $\alpha, \beta$ networks in the hodograph and in the slip-line field completes the proof of an incomplete solution.

The slip-line field in Fig. 5 is valid until $A^{\prime} M^{\prime} S$ becomes tangent to the footing, which corresponds to $0.14 \leqslant L / b \leqslant 1$. For lower values of $L / b$ the slip-line field is extended, as shown in Fig. 6, with $\alpha$ lines tangent to the footing on the left-hand side ( $\beta$ lines on the right-hand side): the entire reasoning remains valid.

Producing an incomplete solution in both cases makes it easier to apply the upper bound approach. The upper bound estimate for the correction factor being denoted $\left[K_{\mathrm{c}}^{\mathrm{s}}(L / b)\right]^{\prime}$, we have:

$$
p_{\mathrm{ult}}=c_{\mathrm{u}} K_{\mathrm{c}}^{\mathrm{s}}\left(\frac{L}{b}\right) N_{\mathrm{c}} \leqslant c_{\mathrm{u}}\left[K_{\mathrm{c}}^{\mathrm{s}}\left(\frac{L}{b}\right)\right]^{\prime} N_{\mathrm{c}}
$$
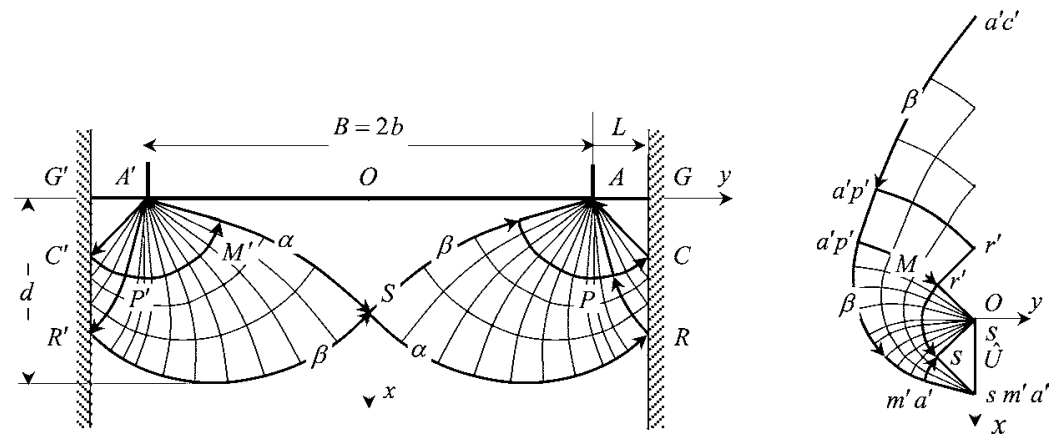

Fig. 5. Slip-line field and hodograph for frictionless walls when $L / b \geqslant 0.14$. 


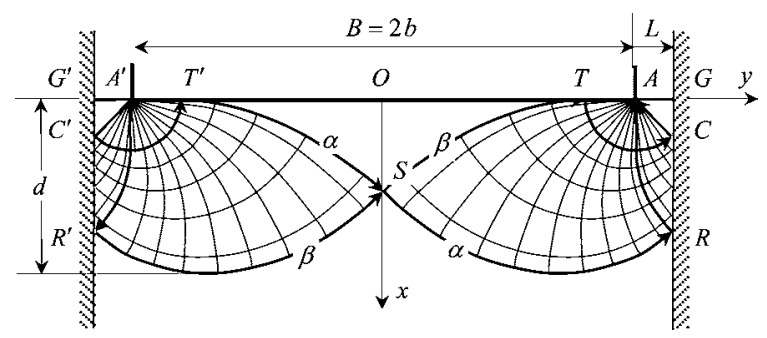

Fig. 6. Slip-line field for frictionless walls when $0<L / b<0.14$.

It follows from the correspondence between the slip-line fields in Figs. 1 and 5 that the same upper bound estimate of the bearing capacity is obtained for a given value of $L / b \geqslant 0.14$ in the "smooth" case and for twice that value in the "rough" case. In other words:

$$
\forall \frac{L}{b}>0.14, \quad\left[K_{\mathrm{c}}^{\mathrm{s}}\left(\frac{L}{b}\right)\right]^{\prime}=\left[K_{\mathrm{c}}^{\mathrm{r}}\left(\frac{2 L}{b}\right)\right]^{\prime}
$$

For smaller values of $L / b$ the correspondence is no more valid but may be retained, if necessary, as a good estimate.

The corresponding results are presented in Fig. 3. The increase of the bearing capacity is not significant for practically relevant values of $L / b$ : it remains smaller than $10 \%$ for $L / b \geqslant 0.36$ and smaller than $20 \%$ for $L / b \geqslant 0.22$. This comes from the fact that, in a comparison with the unlimited soil foundation, the overall increase of the resistance of the constituent materials of the system introduced through the existence of the rigid walls is counterbalanced by the frictionless contact condition.

\section{References}

[1] J. Salençon, The influence of confinement on the bearing capacity of strip footings, C. R. Mecanique 330 (2002) 319-326.

[2] J. Salençon, An introduction to the yield design theory and its applications to soil mechanics, Eur. J. Mech. A 9 (5) (1990) $477-500$.

[3] R. Hill, The Mathematical Theory of Plasticity, Clarendon Press, Oxford, 1950, pp. 182-184.

[4] H. Geiringer, Some recent results in the theory of an ideal plastic body, in: Adv. Appl. Mech., Academic Press, New York, 1953, pp. 197294.

[5] A.P. Green, On the use of hodographs in problems of plane plastic strain, J. Mech. Phys. Solids 2 (2) (1954) 73-80.

[6] J.F.W. Bishop, On the complete solution to problems of deformation of a plastic rigid material, J. Mech. Phys. Solids 2 (1) (1953) $43-53$.

[7] D.J.F. Ewing, R. Hill, The plastic constraint of V. notched tension bars, J. Mech. Phys. Solids 15 (2) (1967) 115-124.

[8] A.M. Puzrin, M.F. Randolph, Generalized framework for the three-dimensional upper bound limit analysis in a Tresca material, J. Appl. Mech. 70 (1) (2003) 91-100. 